\title{
Acute Glomerulonephritis Presenting With PRES: A Report of 4 Cases
}

\author{
EC Wirrell, LD Hamiwka, LA Hamiwka, S Grisaru, X Wei
}

\begin{abstract}
Objective: Posterior reversible encephalopathy syndrome (PRES) occurs most commonly in the setting of known hypertension or use of immunosuppressive agents. Design and Methods: We report four previously-well children who presented acutely with altered mentation, seizures and visual disturbances and were diagnosed with PRES. Results: Only one child had a history of gross hematuria prior to the seizure. All four were discovered to be hypertensive only after onset of their neurological symptoms, and were subsequently diagnosed with glomerulonephritis. All four had rapid resolution of neurological symptoms with adequate treatment of hypertension. Conclusions: Blood pressure must be measured promptly in all children presenting with these symptoms. If elevated, the diagnosis of PRES should be strongly considered and a workup for renal disease pursued.
\end{abstract}

RÉSUMÉ: Qustre observations cliniques de glomérulonéphrite aiguë avec tableau de SERP. Objectif : Le syndrome d'encéphalopathie réversible postérieure (SERP) se rencontre le plus souvent dans le cadre d'une hypertension connue ou de la prise d'immunosuppresseurs. Plan d'étude et méthodes : Nous décrivons quatre enfants en bonne santé qui ont présenté de façon aiguë une détérioration de l'état mental, des convulsions et des troubles visuels, chez qui on a posé un diagnostic de SERP. Résultats : Un seul enfant avait une histoire d'hématurie macroscopique avant les convulsions. On a posé un diagnostic d'hypertension chez tous seulement après le début des symptômes neurologiques et un diagnostic de glomérulonéphrite a été posé par la suite. Les symptômes neurologiques ont disparu rapidement après traitement adéquat de l'hypertension. Conclusions : La pression artérielle doit être mesurée rapidement chez tous les enfants qui présentent ce tableau clinique. Si elle est élevée, il est important de considérer qu'il pourrait s'agir d'un SERP et de procéder à un bilan rénal.

Can. J. Neurol. Sci. 2007; 34: 316-321

Posterior reversible encephalopathy syndrome (PRES), first described in 1996, ${ }^{1}$ is an increasingly recognized complication of hypertension in children. Characteristic symptoms include visual disturbances, altered mentation, seizures, headache and vomiting. Neuroimaging studies show white matter changes suggestive of vasogenic edema that predominantly affect the posterior cerebral hemispheres.

Most reported pediatric cases have occurred in the presence of known hypertension, renal disease or use of immunosuppressive agents, when the suspicion for this diagnosis may be high. ${ }^{2-4}$ When symptoms of PRES occur de novo, in a previously well child, this diagnosis may not be clear-cut. ${ }^{5-7}$

Glomerulonephritis is one of the most common causes of acute hypertension in children, and may be clinically silent early in the course. Edema may be mild, and unrecognized, and less than $30-50 \%$ of children develop gross hematuria. ${ }^{8}$ We report four children who presented with seizures, altered mentation and visual disturbances, and were diagnosed with PRES based on their clinical course and neuroimaging studies. They were discovered to be hypertensive only after presentation with neurological symptoms and were subsequently diagnosed with glomerulonephritis (Table 1). Neurological symptoms resolved with prompt treatment of their hypertension.

From the Division of Pediatric Neurology (ECW, LDH), Departments of Pediatrics and Clinical Neurosciences; Division of Pediatric Nephrology (LAH, SG), Department of Pediatrics; Radiology (XW), University of Calgary, Calgary, AB, Canada.

ReCEIVEd DeCEMBER 15, 2006. ACCEPTED IN FINAL FORM MARCh 10, 2007. Reprint requests to: Elaine Wirrell, Division of Pediatric Neurology, Alberta Children's Hospital, 2888 Shaganappi Trail NW, Calgary, AB, T3B 6A8, Canada. 
Table: Clinical and laboratory values of 4 cases

\begin{tabular}{|c|c|c|c|c|}
\hline & Case 1 & Case 2 & Case 3 & Case 4 \\
\hline Age (years) & 8 & 9 & 9 & 7 \\
\hline $\begin{array}{l}\text { Blood pressure } \\
\text {-admission } \\
\text {-course }\end{array}$ & $\begin{array}{l}140 / 86 \\
\text { Decreased to } \\
\text { normal range } \\
\text { by day } 3\end{array}$ & $\begin{array}{l}167 / 109 \\
\text { Decreased to } \\
140 / 80 \text { by day } \\
2, \text { then slowly } \\
\text { into normal } \\
\text { range over next } \\
3 \text { weeks }\end{array}$ & $\begin{array}{l}149 / 88 \\
\text { Decreased to high } \\
\text { normal range by day } \\
2 \text {, with intermittent } \\
\text { rises to as high as } \\
135 / 80\end{array}$ & $\begin{array}{l}145 / 104 \\
\text { Decreased to normal } \\
\text { range by day } 3\end{array}$ \\
\hline Encephalopathy & $\begin{array}{l}\text { Resolved by } \\
\text { day } 4\end{array}$ & $\begin{array}{l}\text { Resolved by } \\
\text { day } 2\end{array}$ & Resolved by day 2 & Resolved by day 2 \\
\hline $\begin{array}{l}\text { Serum albumin } \\
(\mathrm{g} / \mathrm{l})\end{array}$ & 37 & 39 & 15 (low) & 25 (low) \\
\hline $\begin{array}{l}\text { Serum total } \\
\text { protein }(\mathrm{g} / \mathrm{l})\end{array}$ & Not done & Not done & 48 (low) & Not done \\
\hline $\begin{array}{l}\text { Quantitative } \\
\text { urine protein }(\mathrm{g} / \mathrm{l})\end{array}$ & 0.13 & 0.79 & 3.80 & 1.12 \\
\hline Urinalysis & $\begin{array}{l}>30 \mathrm{RBC} / \mathrm{HPF} \\
5-10 \text { hyaline } \\
\text { casts/LPF }\end{array}$ & $\begin{array}{l}>30 \mathrm{RBC} / \mathrm{HPF} \\
10-20 \text { hyaline } \\
\text { casts/LPF }\end{array}$ & $\begin{array}{l}\text { 5-10 WBC/HPF } \\
5-10 \mathrm{RBC} / \mathrm{HPF} \\
\text { 10-20 granular } \\
\text { casts/LPF }\end{array}$ & $\begin{array}{l}\text { 5-10 WBC/HPF } \\
>30 \mathrm{RBC} / \mathrm{HPF}\end{array}$ \\
\hline C3 $(g / 1)$ & $\begin{array}{l}<0.15 \text { (low) } \\
\text { Repeat at } 2 \\
\text { mos }-1.08\end{array}$ & $\begin{array}{l}0.16 \text { (low) } \\
\text { Repeat at } 3 \\
\text { weeks }-0.88\end{array}$ & 1.22 & 0.15 (low) \\
\hline $\begin{array}{l}\text { Serum urea on } \\
\text { admission } \\
(\mathrm{mmol} / \mathrm{l})\end{array}$ & 6.4 & 6.4 & 14 (high) & 5.5 \\
\hline $\begin{array}{l}\text { Serum creatinine } \\
(\mu \mathrm{mol} / 1) \\
\text {-admission } \\
\text {-follow-up }\end{array}$ & $\begin{array}{l}42 \\
29 \text { (at } 2 \text { mos } \\
\text { follow-up) }\end{array}$ & $\begin{array}{l}57 \\
50 \text { (at } 3 \text { weeks } \\
\text { follow-up) }\end{array}$ & $\begin{array}{l}331 \\
400 \text { (at } 12 \text { mos } \\
\text { follow-up) }\end{array}$ & $\begin{array}{l}62 \\
56 \text { (at 1 week } \\
\text { follow-up) }\end{array}$ \\
\hline
\end{tabular}

\section{CASe 1}

A previously healthy, eight-year-old boy presented with a 5 day history of lethargy, vomiting and diarrhea. On the day of admission, he had complained of difficulty seeing and was bumping into things. In the ER, he had several witnessed focal onset seizures, beginning with visual complaints ("oil on water") followed by unresponsiveness, gulping, drooling and rhythmic right sided twitching followed by secondary generalization.

On examination, his blood pressure was 140/86 and temperature was $37.7 \mathrm{C}$. He was sleepy but roused to voice. $\mathrm{He}$ complained of seeing "dogs" and "gloves on his hand". Neurological examination showed no focal abnormalities but toes were upgoing. General exam showed mild periorbital edema.

Computed tomography scan showed several areas of white matter hypodensity (Figure 1). LP was unremarkable, and culture and HSV PCR were negative. Blood and urine results are shown in Table 1. A metabolic workup, including urine and plasma amino acids, urine organic acids and serum lactate were normal. His throat swab was positive for Streptococcus A, and his ASOT and antiDNAse $B$ titres were elevated at $738 \mathrm{IU} / \mathrm{mL}$ and
$>1: 1360$, respectively but ANA and anti-DNA were negative. His diagnosis was presumed post-streptococcal glomerulonephritis. His EEG showed slowing in the left posterior quadrant at T5/O1 and rare right frontal spikes at F4. The MRI showed multiple areas of T2 hyperintensity, most pronounced in the posterior temporal and occipital-parietal regions (Figure 1).

He received lorazepam $0.1 \mathrm{mg} / \mathrm{kg}$ IV followed by a $20 \mathrm{mg} / \mathrm{kg}$ loading dose of phenytoin. His blood pressure remained intermittently elevated to as high as $135 / 96$ over the next 24 hours and he remained encephalopathic with no further seizures. He received nifedipine prn, and commenced amlodipine therapy with control of his blood pressure and normalization of his mental status. Phenytoin was stopped 3 months later, and amlodipine was discontinued one month after admission. He has remained well over the subsequent 2 years of follow-up with normal renal function and his MRI at 2 years was normal.

\section{CASE 2}

A nine-year-old previously healthy boy presented to the emergency department with a focal seizure beginning with 
complaints of blurred vision followed by left hand twitching, loss of consciousness and drooling. Post-ictally, a left sided paresis was noted. He had a history of malaise and low grade fever 7-8 days earlier, left temporal throbbing headaches and nausea for the past 3-4 days and blurred vision and vomiting for the past day. His initial blood pressure was elevated at 167/109. On exam, he was drowsy and somewhat confused. He had a left facial droop and left upgoing toe but moved all limbs to noxious stimuli.

His head CT scan showed a hypodensity in the right occipital region (Figure 2) and his CSF examination was normal. His blood and urine results are shown in Table 1. His ASOT was elevated at $1277 \mathrm{IU} / \mathrm{mL}$ and ANA was negative. A metabolic workup including plasma and urine amino acids, urine organic acids, carnitine, lactate and urine metabolic screen was normal. CSF analysis was unremarkable. His diagnosis was presumed post-streptococcal glomerulonephritis. His EEG showed right occipital slowing and epileptiform discharge at $\mathrm{O} 2$ and $\mathrm{P} 4$. Magnetic resonance imaging T2 hyperintensities were seen in the right parieto-occipital lobe and most of the lesions had no restricted diffusion (Figure 2).

$\mathrm{He}$ received a loading dose of $20 \mathrm{mg} / \mathrm{kg} \mathrm{IV}$ phenytoin and was empirically treated with ceftriaxone and acyclovir. His blood pressure was controlled acutely with prn nifedipine and he was commenced on amlodipine therapy. His neurological examination normalized by 24 hours after presentation. He was discharged on carbamazepine and amlodipine. Two weeks later he had recurrence of blurred vision with hypertension, but symptoms resolved with control of his blood pressure. A followup MRI 3 months after initial presentation showed complete resolution of the lesions.

\section{CASe 3}

A previously well, nine-year-old boy presented with newonset, recurrent seizures, comprised of rhythmic horizontal nystagmus, followed by unilateral right or left facial twitching, at times with secondary generalization lasting up to five minutes.

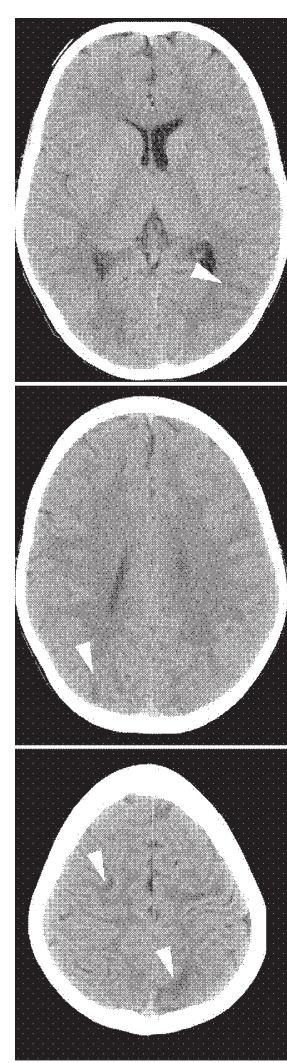

C- CT
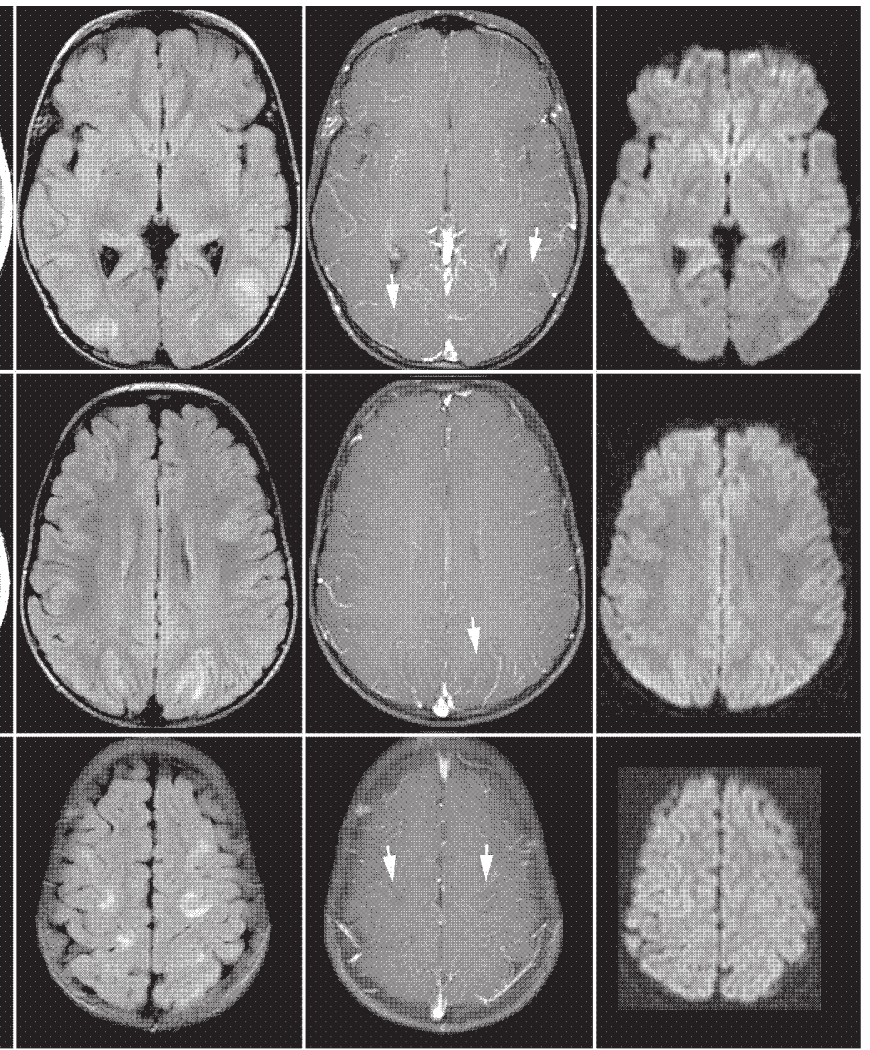

FLAIR

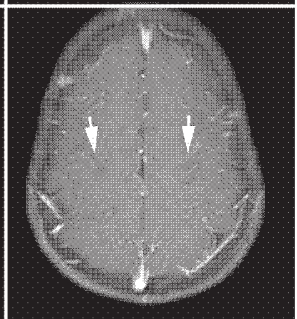

Gd+ T1W
DWI

Figure 1: Neuroimaging of Case 1 demonstrates typical findings of reversible posterior leukoencephalopathy. CT without contrast material five days after onset of neurological symptoms reveals multiple small areas of subcortical white matter hypodensity (arrowheads) predominantly in the posterior temporal and occipito-parietal regions. Fast fluid-attenuated inversion recovery images (FLAIR, TR 8500/TE 93/TI 2200/ETL 15) at slightly different cuts to CT show multiple areas of subcortical white matter hyperintensity, fairly symmetric. These lesions demonstrate hypointense T1 signal without enhancement (arrows) on post-contrast T1-weighted images (Gd+T1W, TR 635/TE 17). No restricted diffusion is seen on diffusion-weighted images $\left(D W I, b=1000 \mathrm{~s} / \mathrm{mm}^{2}\right)$ to indicate ischemia/infarction. 


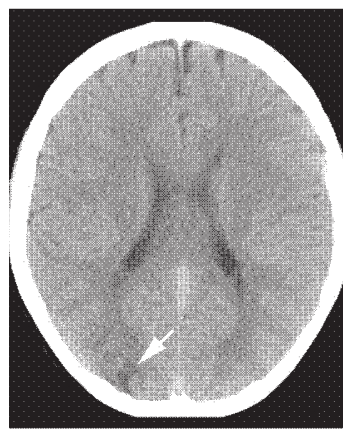

C- CT

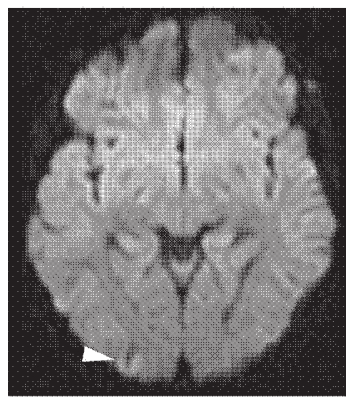

DWI

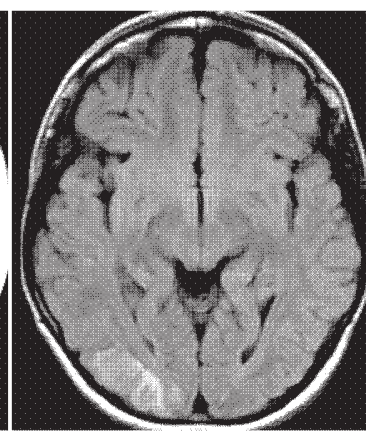

Axi FLAIR

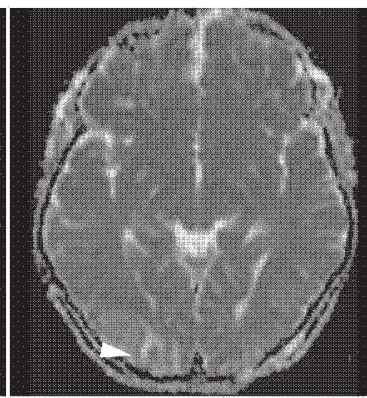

$A D C$

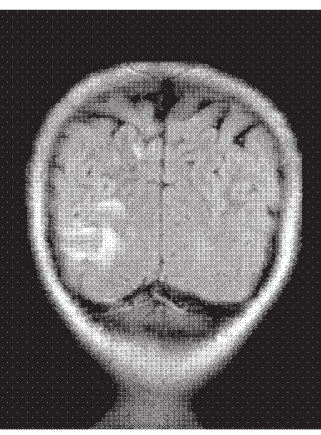

Cor FLAIR

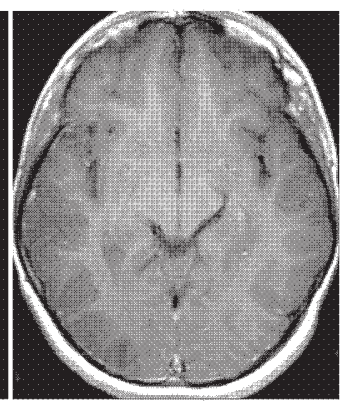

$\mathrm{Gd}+\mathrm{T} 1 \mathrm{~W}$

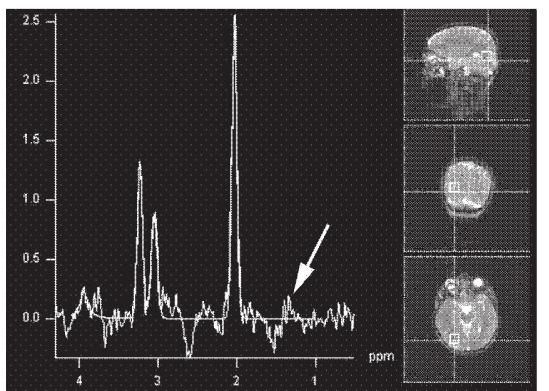

MRS

He had a one week history of intermittent vomiting, abdominal pain and headache. No visual symptoms or mental status changes were reported prior to seizure onset.

At presentation, his blood pressure was 153/102 and mild periorbital edema was noted. He was stuporous but withdrew all limbs symmetrically to deep pain. Reflexes were brisk but symmetric and both toes were upgoing. Fundoscopic exam showed normal disc margins.

Blood and urine results are shown in the Table. Electrolytes were unremarkable. A CT head showed bilateral hypodensities in both posterior parietal regions. The MRI showed T2 hyperintensities in both parietal lobes without restricted diffusion and multiple, discrete $\mathrm{T} 2$ hyperintensities in the centrum semiovale. His EEG showed bioccipital slowing but not epileptiform discharge.

He was loaded with $20 \mathrm{mg} / \mathrm{kg}$ of phenytoin IV and received repeat labetolol boluses followed by amlodipine to treat his hypertension. With control of his blood pressure, he had no
Figure 2: Neuroimaging of Case 2 shows abnormalities consistent with reversible posterior leukoencephalopathy. CT without contrast material $(C-C T)$ at presentation demonstrates a small area of hypodensity (short arrow) in the right occipital lobe. MRI was performed four hours later. Axial and coronal fast fluid-attenuated inversion recovery images (FLAIR,TR 8500/TE 93/TI 2200/ETL 15) reveal several areas of predominantly subcortical hyperintensity in right occipito-parietal region. Most of the lesions have no restricted diffusion except for a small area in the occipital cortex (arrowhead), which demonstrates hyperintensity on diffusion-weighted images (DWI, $\left.b=1000 \mathrm{~s} / \mathrm{mm}^{2}\right)$ and appears dark on apparent diffusion coefficients (ADC) map. The lesions do not enhance on post-contrast T1-weighted sequence $((G d+T 1 W, T R$ 635/TE 17). On the singlevoxel MR spectroscopy (MRS, TE $=270 \mathrm{msec}$ ) over the right occipital lesion, a small peak of lactate is seen (long arrow). further seizures and by the second day of admission, his mental status had returned to normal. Antiepileptic medication was discontinued and he has remained seizure-free. IgA nephropathy was later diagnosed by kidney biopsy and he subsequently required renal replacement therapy with peritoneal dialysis for 7 months. His most recent GFR is less than 20, and his creatinine remains elevated at 400 .

A repeat MRI 17 months later showed resolution of changes in the posterior parietal lobes, but persisting multiple, small T2 hyperintensities in the deep white matter of the centrum semiovale.

\section{CASe 4}

A seven-year-old girl was transferred to our center following a left-sided focal seizure lasting 5-10 minutes. She complained of a one week history of daily headache, vomiting and decreased appetite. She had been diagnosed with impetigo 12 days prior to 
presentation which was treated with cephalexin. At the time of presentation with her seizure, it was noted that she had passed "tea-colored" urine for the preceding three days. On exam, she was afebrile and had a blood pressure of 145/104. She was irritable but roused easily with stimulation. Neurological examination was unremarkable except for a left Babinski sign.

Her head CT was normal but MRI showed T2 hyperintensities predominantly affecting the subcortical white matter in occipital and posterior parietal and temporal regions, as well as the right cerebellar hemisphere. Diffuse background slowing predominantly affecting posterior head regions was seen on EEG but there were no epileptiform discharges. Blood and urine results are shown in Table 1 . ASOT was elevated at $640 \mathrm{IU} / \mathrm{mL}$. CSF analysis was unremarkable.

She was diagnosed with post-streptococcal glomerulonephritis. She received $2 \mathrm{mg}$ lorazepam IV followed by a 15 $\mathrm{mg} / \mathrm{kg}$ load of IV phenytoin at the time of her seizure, but was not maintained on antiepileptic medication and had no subsequent events. Her hypertension was treated acutely with nifedipine and she was discharged home on amlodipine.

\section{Discussion}

The diagnosis of PRES should be considered in any child presenting with new onset seizures, encephalopathy and visual symptoms. This condition responds promptly to adequate control of blood pressure, and the long-term neurological prognosis is extremely favorable. Prior reported cases of PRES due to renal disease in children have predominantly occurred after the diagnosis of the renal disease was established. ${ }^{2-6}$ However, three prior case reports describe previously well children presenting with symptoms of PRES, who were ultimately diagnosed with poststreptococcal glomerulonephritis. ${ }^{7-10}$ The diagnosis of poststreptococcal glomerulonephritis in three of our cases was made based on presentation with a nephritic picture, high ASOT levels, low $\mathrm{C} 3$ and complete resolution of renal disease on follow-up. Our four cases from a single centre suggest that the association between PRES undiagnosed renal disease such as poststreptococcal glomerulonephritis is not rare, and probably under-recognized - investigation for renal disease must be pursued with this clinical presentation.

The pathophysiology of PRES involves vasogenic rather than cytotoxic edema. ${ }^{11}$ Cerebral autoregulation maintains a relatively constant cerebral blood flow over a range of mean arterial blood pressure, thus protecting the brain from acute changes in blood pressure. However, at high mean arterial pressures, autoregulation fails, leading to arteriolar vasodilation and endothelial dysfunction, resulting in disruption of the bloodbrain barrier and capillary leakage. The white matter is predominantly affected as it is less tightly packed than the cortex. The posterior brain appears to be preferentially affected because of diminished sympathetic innervation. ${ }^{12}$ Children with acute onset of hypertension are probably more at risk than those with chronic hypertension, because they have not yet developed adaptive vascular changes. Posterior reversible encephalopathy syndrome can also be seen with immunosuppressive drugs. The pathophysiology in this setting is less clear, but may involve damage to the vascular endothelium resulting in vasospasm, reduced tissue perfusion, activation of the coagulation cascade and extravasation of fluid. ${ }^{1}$
The differential diagnosis of acute seizures, encephalopathy and focal or multifocal white matter abnormalities on imaging include infarction, vasculitis, demyelinating disorders, encephalitis and mitochondrial cytopathies. While neuroimaging abnormalities in PRES are seen maximally in the white matter of the parietal and occipital regions, lesions can be more extensive, spreading into the cerebellum, frontal regions, basal ganglia, thalami, brain stem and corpus callosum, suggesting a diagnosis of demyelinating disease. ${ }^{13}$ Co-existent cortical involvement is common, occurring in up to $94 \% .^{1,14,15}$ Although abnormalities may be seen on computed tomography (CT) scan, fluidattenuated inversion recovery (FLAIR) MRI sequences are much better at showing the extent of the hyperintense lesions and the degree of cortical involvement. The calcarine and paramedian part of the occipital lobe are classically spared, helping to distinguish PRES from bilateral posterior cerebral artery infarction. ${ }^{1}$ Diffusion-weighted MR imaging (DWI) sequences are helpful to discriminate mitochondrial encephalopathy and venous infarction, in which the lesions typically show restricted diffusion. The majority of lesions in PRES show iso or slightly hyperintense signal on DWI but increased apparent diffusion coefficient (ADC) consistent with vasogenic edema, as opposed to decreased ADC values usually seen with infarction. ${ }^{15}$ Rarely, very high tissue perfusion pressure may lead to decreased cerebral blood flow, with resulting ischemia and cytotoxic edema, manifested by an area of increased signal on DWI and decreased signal on the ADC map. ${ }^{15}$ The lesions of PRES usually do not enhance on post-contrast images. The MR spectroscopy results have varied, but evidence of subtle metabolic changes including high lactate ${ }^{16}$ and increased choline and creatine and mildly decreased $\mathrm{N}$-acetyl aspartate ${ }^{17}$ has been reported.

In conclusion, blood pressure is an important vital sign to attend to in all children presenting with visual complaints, seizures and/or encephalopathy. If elevated, the diagnosis of PRES should be strongly considered and a workup for renal disease pursued. Prompt treatment of hypertension results in resolution of neurological symptoms.

\section{REFERENCES}

1. Hinchey J, Chaves C, Appignani B, Breen J, Pao L, Wang A, et al. A reversible posterior leukoencephalopathy syndrome. New Engl J Med. 1996;334:494-500.

2. Ohta T, Sakano T, Shiotsu M, Furue T, Ohtani H, Kinoshita Y, et al. Reversible posterior leukoencephalopathy in a patient with Wegener granulomatosis. Pediatr Nephr. 2004;19:442-4.

3. Soylu A, Kavukcu S, Turkmen M, Akbas Y. Posterior leukoencephalopathy syndrome in poststreptococcal acute glomerulonephritis. Pediatr Nephr. 2001;16:601-3.

4. Ozcakar ZB, Ekim M, Fitoz S, Teber S, Hizel S, Acar B, et al. Hypertension induced reversible posterior leukoencephalopathy syndrome: a report of two cases. Eur J Pediatr. 2004;163:728-30.

5. Ohtomo Y, Takada M, Fujinaga S, Murakami H, Yamashiro Y. Hypertensive encephalopathy in a boy with biopsy-proven acute post-streptococcal glomerulonephritis. Pediatr Int. 2005;47: 323-5.

6. Yang MH, Sheu JN, Wang SJ. Cortical blindness in a boy with acute glomerulonephritis. J Formos Med Assoc. 2003;102:52-4.

7. Froehlich T, Sandifer S, Varma P, Testa F. Case report: two cases of hypertension-induced reversible posterior leukoencephalopathy syndrome secondary to glomerulonephritis. Curr Opin Pediatr. 1999;11:512-18.

8. Fux CA, Bianchetti MG, Jakob SM, Remonda L. Reversible encephalopathy complicating post-streptococcal glomerulonephritis. Ped Infect Dis J. 2006;25:85-7. 
9. Aeby A, David P, Fricx C, Jissendi P, Blecic S, Van Bogaert P. Posterior reversible encephalopathy syndrome revealing acute post-streptococcal glomerulonephritis. J Child Neurol. 2006;21:250-1.

10. Pan CG. Glomerulonephritis in childhood. Curr Opin Pediatr. 1997;9:154-9.

11. Brubaker LM, Smith JK, Lee YZ, Lin W, Castillo M. Hemodynamic and permeability changes in posterior reversible encephalopathy syndrome measured by dynamic susceptibility perfusionweighted MR imaging. AJNR Am J Neuroradiol. 2005;26: 825-30.

12. Owman C, Edvinsson L, Nielson KC. Autonomic neuroreceptor mechanisms in brain vessels. In: Fuxe K, Olson L, Zotterman Y, editors. Dynamics of degeneration ad growth in neurons. New York: Pergamon; 1974. p. 535-60.
13. Ito S, Nezu A, Matsumoto C, Aihara Y, Yokota S. Acute disseminated encephalomyelitis and poststreptococcal acute glomerulonephritis. Brain Dev. 2002;24:88-90.

14. Casey SO, Sampaio RC, Michel E, Truwit CL. Posterior reversible encephalopathy syndrome: utility of fluid-attenuated inversion recovery MR imaging in the detection of cortical and subcortical lesions. Am J Neuroradiol. 2000;21:1199-206.

15. Covarrubias DJ, Luetmer PH, Campeau NG. Posterior reversible encephalopathy syndrome: prognostic utility of quantitative diffusion-weighted MR images. Am J Neuroradiol. 2002; 23:1038-48.

16. Kwon S, Koo J, Lee S. Clinical spectrum of reversible posterior leukoencephalopathy syndrome. Pediatr Neurol. 2001;24:361-4.

17. Eichler FS, Wang P, Wityk RJ, Beauchamp NJ, Barker PB. Dynamic metabolic abnormalities in reversible posterior leukoencephalopathy syndrome. Am J Neuroradiol. 2002;23: 833-7. 